\title{
UNIÃO POLIAFETIVA: FAMÍLIA DE FATO. E DE DIREITO?
}

\author{
POLY-UNION: FAMILY IN FACT. AND BY LAW?
}

\section{RESUMO}

O conceito de família passa por constantes transformações no Direito brasileiro a fim de se adaptar às demandas da sociedade. Novas realidades se apresentam como desafios porque nem sempre encontram respostas objetivas no ordenamento. Apesar desse movimento ser comum a outros ramos, no Direito de Família ele se mostra dramático, pois envolve direitos fundamentais. A viabilidade jurídica da união poliafetiva enquanto entidade familiar perpassa essa questão. De um lado, a invocação do princípio da monogamia como norteador das relações conjugais. De outro, a observância de princípios hierarquicamente superiores que legitimariam tais relações. Assim, os princípios fundamentais da igualdade, liberdade e pluralismo revelariam um verdadeiro direito de constituir família. Tangenciando o problema, os princípios gerais da boa-fé e da segurança jurídica também serviriam de balizas para se analisar a conformidade das relações. Considerando essa escala axiológica, eventual conflito envolvendo os princípios jurídicos elencados deve analisar sua posição nessa estrutura.

Palavras-chave: União poliafetiva. Entidade familiar. Princípios.

\section{ABSTRACT}

Family concept has constantly changed in Brazilian Law to adapt to new demands of society. New situations present as challenges that not always have answers. Although this movement is common to all branches, in Family Law it assumes a dramatic character as it involves the protection of fundamental rights. The legal feasibility of poly-union as a family entity runs through this question. On the one hand, the invocation of a principle of monogamy as guiding marital relations. On the other, the observance of hierarchically superior principles that would legitimize such relations. Thus, the fundamental principles of equality, liberty, pluralism, would reveal a true right to constitute a family. Related to this matter, general principles of good faith and legal certainty would also serve as a framework for analyzing the conformity of situations. Considering that axiological scale, eventual conflict involving those juridical principles must to analyze its position in this structure.

Keywords: Poly-union. Family entity. Principles.

Lívia H. O. Poggiali

Universidade FUMEC. E-mail: liviahdeoliveira@gmail.com

Luís C. B. Gambogi

Universidade FUMEC. E-mail: gambogi@fumec.br 


\section{Introdução}

O conceito de família passa por constantes transformações no Direito brasileiro a fim de se adaptar às demandas da sociedade. Novas realidades se apresentam como desafios aos operadores do Direito que nem sempre encontram respostas objetivas no ordenamento. Apesar desse movimento de permanente adequação ser comum a todos os ramos, no Direito de Família ele se mostra dramático na medida em que envolve a realização de direitos fundamentais.

$\mathrm{O}$ presente trabalho analisa a viabilidade jurídica da união poliafetiva enquanto entidade familiar. Ou seja, a possibilidade de se conferir efeitos legais a essa relação, assim considerada quando envolver mais de duas pessoas e apresentar os elementos caracterizadores das uniões de fato. Conforme será abordado adiante, há diferentes conceitos e formatos de relações poliamorosas. Contudo, será objeto de análise aquela que vem sendo denominada "poliafetiva" - especialmente no meio jurídico - quando se entende ser semelhante a uma "união estável de várias pessoas".

A principal fonte do trabalho é o direito positivo, em especial os dispositivos que tratam da família, dos princípios e dos direitos fundamentais, além dos requisitos apontados pela doutrina como essenciais à configuração das entidades familiares. Para tanto, utilizou-se a pesquisa bibliográfica com base em livros e artigos de periódicos, bem como a pesquisa documental a partir de documentos e reportagens relacionados ao tema.

A análise da questão proposta é de extrema relevância social e jurídica, uma vez que há atualmente um verdadeiro impasse sobre a validade dessa configuração familiar. A discussão tomou repercussão com a formalização de algumas relações mediante lavratura de escritura pública e, recentemente, com a decisão do Conselho Nacional de Justiça (CNJ) proibindo os cartórios de praticar tais atos ${ }^{1}$.

A união poliafetiva é uma realidade para a qual o Direito precisa oferecer respostas. As dúvidas acerca da possibilidade de reconhecimento acabam gerando exclusão jurídica e social, além de instaurar um estado de insegurança. Tal fato pode ser evidenciado pelo fundamento da decisão do CNJ: ausência de previsão legal e jurisprudência sobre a matéria. Não obstante, é importante pontuar que o CNJ tem competência administrativa e, portanto, essa decisão apenas vincula a atuação cartorária, não implicando em manifestação quanto à possibilidade ou não de reconhecimento judicial.

Para além da previsão legal, na seara jurídica, o grande embate em torno da questão repousa no fato de que tais relações, ainda que preencham os requisitos exigidos para as uniões estáveis, quais sejam: afetividade, publicidade, estabilidade e

1 A decisão foi tomada pelo Plenário do CNJ em 26/06/18 no âmbito do Pedido de Providências ooo1459o8.2016.2.00.0000. 
animus de família² , encontram óbice no modelo monogâmico de relações conjugais previsto no ordenamento3.

Contudo, como se verá, na medida em que a instituição familiar é campo de realização da personalidade, a Constituição Federal, ao trazer os princípios fundamentais, dispõe sobre critérios de integração do sistema normativo. Nesse sentido, a igualdade, a liberdade e o pluralismo, enquanto desdobramentos da cláusula geral da dignidade da pessoa humana, impõem o reconhecimento dessas entidades. Além disso, neste estudo destaca-se o importante papel dos princípios gerais da boa-fé e da segurança jurídica. Entendemos que estes intermediam a análise da conformação de situações concretas aos valores protegidos pelo ordenamento.

\section{O sistema jurídico enquanto conjunto escalonado de regras e princípios}

A discussão acerca do reconhecimento das uniões poliafetivas encontra seus embates mais calorosos quando da análise da monogamia enquanto princípio jurídico norteador das relações conjugais do Direito de Família. Isso porque, em que pese não haver consenso sobre sua existência enquanto princípio ${ }^{4}$, fato é que inúmeras regras do ordenamento jurídico brasileiro trazem em seu conteúdo normativo a proteção do modelo monogâmico de família. Antes de adentrar na exposição de tais regras, necessário se faz abordar, ainda que brevemente, a distinção entre regras e princípios.

Como se sabe, ambos são espécies de normas e possuem diferentes funções, visando, em seu conjunto, conferir equilíbrio ao sistema jurídico. De acordo com Ávila (2007), "um sistema só de princípios seria demasiado flexível, pela ausência de guias claros de comportamento (...). E um sistema só de regras, aplicadas de modo formalista, seria demasiado rígido, pela ausência de válvulas de abertura para o

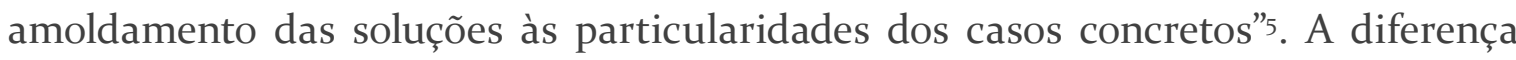
entre tais espécies é, portanto, qualitativa.

Os princípios, a partir de seu conteúdo abstrato, apresentam-se como diretrizes, indicando uma "razão de ser". Como a própria etimologia sugere, são pontos de partida e, não sem motivo, possuem forte carga valorativa, pois é por meio deles que são consignados no ordenamento os bens jurídicos mais relevantes

2 Numa conjugação do que prevê o art. 1.723 do Código Civil como requisitos da união estável e a doutrina majoritária ao trazer os elementos caracterizadores das entidades familiares. Por todos: Lôbo (2002) que elenca os aspectos comuns e indispensáveis à configuração de família: afetividade, estabilidade, ostensibilidade.

3 Por todos: Gonçalves (2015) defende a inviabilidade jurídica de se reconhecer a união poliafetiva enquanto entidade familiar tendo em vista o não atendimento ao princípio da monogamia que entende pautar o afeto (confiança) e boa-fé objetiva (conduta proba) no contexto das relações familiares.

4 A título exemplificativo tem-se a obra de Pereira (2006) que inclui a monogamia no rol de princípios do Direito de Família e, de outro lado, Silva (2013) que defende sua superação.

5 Ávila (2007:120). 
para a sociedade, passando a funcionar como vetores de interpretação, integração e produção normativas.

Nessafunçãodeestruturaçãodosistemaépossívelidentificarumescalonamento dentre os princípios de modo a se indicar quais devem ser observados ou priorizados em caso de aparente conflito. Num ordenamento que adota a Constituição como requisito de validade de todo o sistema, é o texto constitucional que apresenta os princípios mais importantes, de forma expressa, notadamente quando dispõe sobre os fundamentos e objetivos do Estado e as garantias e direitos por ele protegidos.

Dentre as várias classificações possíveis, Gabrich (2007), a partir da sistematização trazida por Bergel, aponta três classes de princípios: fundamentais, gerais e específicos. Como fundamentais, estão compreendidos aqueles princípios assim indicados pela Constituição que veiculam os valores mais importantes à sociedade e se mostram essenciais para qualquer organização social. À luz da Constituição Federal de 1988, cita-se a igualdade, a liberdade, o pluralismo. Tais princípios vinculam não apenas a interpretação normativa, mas também a própria produção legislativa, tornando inconstitucional aquilo que os afronta. Os princípios gerais, por sua vez, estão subordinados aos fundamentais, embora não necessariamente derivem destes ou mesmo estejam expressos na Lei Maior. Por esse motivo, nem sempre vinculam o legislador infraconstitucional, a depender de onde retiram seu fundamento de validade e também de onde estão previstos. De todo modo, os princípios gerais estabelecem uma base jurídica aplicável a um ou mais ramos do Direito e a qual estão ligados os princípios específicos e as regras deles decorrentes. Dentre eles, é possível apontar a boa-fé e a segurança jurídica. Por fim, os princípios específicos têm aplicação limitada a um ramo ou mesmo a institutos jurídicos, mas também funcionam como diretrizes normativas, ainda que a um microssistema, a exemplo dos princípios da eficiência (Direito Administrativo), da afetividade (Direito de Família), da economia processual (Processo Civil).

Assim, os princípios convivem em determinado sistema e devem ser aplicados conjuntamente dentro da estruturação que lhes é própria. Eventual colisão entre eles no caso concreto deve observar essa hierarquia e "peso" diante de determinada situação. De todo modo, cabe destacar que essa análise deve ser operada com cautela pelo intérprete, pois exatamente devido ao conteúdo abstrato dos princípios, a atividade de valoração confere grande margem à subjetividade, tendendo a levar à quebra de isonomia e segurança só justificável diante de situações excepcionais.

As regras, em caráter diametralmente oposto, possuem um conteúdo normativo objetivo, determinando um padrão de conduta a ser seguido. Elas derivam dos princípios e se distinguem por oferecerem soluções apriorísticas que devem ser observadas para maior estabilidade jurídica. Seus enunciados trazem relatos descritivos, claros e diretos, por vezes já prevendo as exceções e as consequências pela inobservância de seus comandos. Por esse motivo, são clássicos os critérios de Bobbio (1995) para a solução de conflitos normativos envolvendo as regras, vez que - diferentemente dos princípios - não é possível a aplicação simultânea de mais de uma regra em uma mesma situação jurídica. Assim, em caso de aparente antinomia 
devem ser verificadas a cronologia, a especialidade e a hierarquia, a fim de se chegar a apenas uma regra a ser aplicada mediante a subsunção (aplicação da norma ao caso concreto). Nesse ponto, não há que se falar em aplicação conjunta ou em graus, já que sua incidência obedece a lógica da vigência, especificidade e validade.

Feita essa distinção, passamos, a seguir, à identificação das regras no ordenamento que, em nossa visão, tutelam um modelo monogâmico de família e a discussão acerca da natureza jurídica da monogamia no sistema brasileiro.

\section{Monogamia: regra moral ou princípio jurídico?}

Como sustenta Gonçalves (2015), inúmeros são os dispositivos no Código Civil que demonstram a proteção ao modelo monogâmico. Dentre eles: o dever de fidelidade recíproca entre os cônjuges (art. 1566, inciso I), o impedimento para casar de pessoa já casada (art. 1521, inciso VI), o adultério como possível causa de dissolução da sociedade conjugal (art. 1573, inciso I), o dever de lealdade entre os companheiros na união estável (art. 1724), a denominação de concubinato para as relações não eventuais entre impedidos de casar (art. 1727). E, avançando nessa lista, Figueiredo (2011) indica a vedação de doação de bens do cônjuge adúltero ao concubino (art. 550), a vedação da nomeação do concubino como herdeiro ou legatário do testador casado (art. 1.801, inciso III), a extinção do direito a alimentos do credor que vier a ter relação concubinária (art. 1708), a impossibilidade de o concubino receber alimentos (art. 1.624) ${ }^{6}$, a impossibilidade de o concubino figurar como beneficiário de seguro de vida do consorte (art. 793).

No Código Penal, por sua vez, tem-se a tipificação da bigamia como crime no art. 235, dentro do Título VII dedicado aos crimes contra a família. O caput do dispositivo descreve tal conduta como sendo a situação na qual a pessoa casada contrai novo casamento. Interessante observar que o $\S^{0}$ do dispositivo pune, inclusive, aquele que, mesmo não sendo casado, contrai casamento com pessoa casada, sabendo dessa circunstância. A repercussão dessas condutas no âmbito criminal demonstra o grande repúdio social a tais práticas, vez que o Direito Penal possui natureza fragmentária e subsidiária, ou seja, configura a última etapa de proteção de um bem jurídico e apenas deve ser invocado quando os outros meios e ramos do Direito tiverem se mostrado insuficientes. Cabe lembrar que, se hoje a reprimenda está restrita ao duplo registro de casamento (bigamia) ${ }^{7}$, até pouco tempo - mais precisamente com a edição da lei 11.106/o5 que revogou o antigo art. 240 do Código Penal - o adultério também era crime.

Nesse ponto, verifica-se que é grande o aparato legal traduzido em regras jurídicas que ultrapassam a esfera civil e o Direito de Família que têm como pano de

6 Interpretação a partir do art. 1.694 do Código Civil que não o prevê no rol de legitimados.

7 Entende-se que os efeitos penais não se estendem à união estável já que não está prevista expressamente no dispositivo penal e a interpretação nesse ramo deve ser restritiva. A respeito: Masson (2015). 
fundo o modelo monogâmico. É a partir desses vários dispositivos infraconstitucionais que se funda a discussão se a monogamia configuraria ou não um princípio jurídico. Porém, antes de classificá-la ou não como princípio, questionamos: por que teria o ordenamento jurídico incorporado a monogamia?

\subsection{As origens da monogamia e sua incorporação na lei}

Engels (1984), em sua clássica obra sobre as origens do modelo monogâmico na organização da sociedade, indica ser a monogamia uma construção histórica, fruto da evolução das formas de família e do surgimento da propriedade privada ${ }^{8}$.

O autor sustenta que a família monogâmica não teve como causa condições naturais, tampouco surgiu como forma mais elevada de matrimônio. A monogamia foi imposta à mulher como forma de garantir a presunção de paternidade e, consequentemente, não afetação da herança. Representou o triunfo da propriedade privada e a dominação de um sexo pelo outro: "o primeiro antagonismo de classes que apareceu na história (...)”. E continua afirmando que veio acompanhada de sua contradição representada pelas figuras sociais do adultério e da prostituição. Assim, a poligamia ${ }^{10}$ continuou sendo praticada pelos homens e aceita socialmente, já que não seria capaz de prejudicar a herança.

Complementando a teoria de Engels, Santiago (2015) destaca a existência de outras explicações quanto à origem da monogamia, a exemplo do estudo da antropóloga Helen Fisher que credita ao hábito nômade dos povos primitivos a necessidade de se manter um único parceiro. Isso porque na medida em que estavam constantemente mudando de território em busca de alimentos, era impossível ao macho nômade coletar e defender recursos para um grupo de mulheres. Por outro lado, para as mulheres, a união por pares se mostrava como único vínculo viável e durava apenas tempo suficiente para o término da infância da prole.

Assim, percebe-se que, em que pese não ser um consenso, para ambas as relevantes teorias acima mencionadas, a monogamia não aparece como um formato conjugal natural, mas como um regime surgido com estreitas ligações econômicas. Tanto que Engels (1984) indica que na sua origem entre os romanos, a palavra "família" designava o conjunto de escravos de um homem. Também neste sentido, Oliveira (2017) afirma que na vigência do Direito Romano imperava tal modelo de família, com a prevalência da figura paterna que exercia domínio e autoridade sobre a esposa, filhos e escravos, com o pátrio poder sendo exercido até a sua morte. Segundo a

8 Friedrich Engels na obra A origem da família, da propriedade privada e do Estado tomando como base o estudo etnográfico de Lewis Morgan Ancient Society (1877) aponta que a análise da história primitiva demonstra estágios de evolução da família em que a monogamia não estava presente, notadamente no estado selvagem de cultura em que se observava o "matrimônio por grupos".

9 Engels (1984:70).

10 Utilizando da classificação trazida por Ruzyk (2005:195) trata-se de uma poligamia exógena, ou seja, a existência de conjugalidades exteriores a uma comunidade familiar originária. 
autora, juntamente com a decadência do Império Romano, se observou a expansão do cristianismo, que introduziu a regulação da família pelo Direito Canônico, sobretudo no ocidente, o que perdurou durante a Idade Média.

A esse respeito, Silva (2013) demonstra que o Direito Canônico delineou toda a concepção de família e conjugalidade da época, permanecendo influente mesmo após as revoluções burguesas. Segundo ele, a Igreja Católica estruturou o estatuto jurídico da família através dos XII cânones, dentre os quais se destaca o cânone II que consagrou a monogamia como princípio estruturante do casamento ${ }^{11}$. Ainda conforme o autor, a aplicação das normas do Direito Canônico encontrou em Portugal rápida adesão, sendo um dos primeiros países a incorporar tal regulamentação matrimonial ao seu ordenamento jurídico, o que se estendeu para o Brasil colônia. E tal influência também se verificou em outros países católicos no ocidente, como França, Espanha e Itália, fazendo da regulação da Igreja a lei do próprio Estado. Essa influência sobreviveu mesmo após a Revolução Francesa de 1789 que representou, ideologicamente, o rompimento do Estado com a Igreja. O Código Civil francês de 1804 se mostrou alinhado aos princípios constitucionais de liberdade, mas não evoluiu em matéria matrimonial. Talvez pelo fato de que o modelo conjugal utilizado, baseado no casamento monogâmico, atendia à perspectiva patrimonialista da codificação civil da época. Também no Código Civil brasileiro de 1916 foram mantidas as características da família patriarcal e sua perspectiva patrimonialista, uma vez que inspirado no francês. E, como efeito, conforme apontado, houve a geração de um estatuto jurídico de exclusão social, pois "família” era apenas aquela formada pelo casamento.

Portanto, o que se verifica é que a normatização (ou melhor: "normalização") da família em torno do casamento monogâmico deixou, historicamente, arranjos familiares à margem da sociedade, na esteira do que se convencionou, em cada época, como um modelo a ser seguido, um ideal moral. Ruzyk (2006), a partir da constatação de que a monogamia endógena - ou seja, "uma única conjugalidade dentro de uma mesma comunidade familiar"12 - é um dado histórico nas sociedades ocidentais, indica que essa estabilidade verificada no tempo trouxe uma natureza estrutural, representando um padrão-médio dessas sociedades. Assim, para o autor, diferentemente de um princípio jurídico, a monogamia traduz certa "moral social média” e daí o porquê de inúmeros dispositivos legais trazerem a proteção a essa característica.

Apesar de reconhecer o forte conteúdo moral, Pereira (2006) entende ser a monogamia um princípio organizador das relações conjugais. Argumenta, para tanto,

11 Silva (2013) indica que a Igreja Católica estruturou o estatuto jurídico da família através da promulgação dos doze cânones do Concílio de Trento em 1563 e também do chamado decreto Tametsi. Dentre eles, destacam-se o cânone I que declarou o casamento como um dos sete sacramentos da Igreja Católica, determinando sua autoridade para dispor sobre a validade e regulamentação, o cânone II que consagrou a monogamia como princípio estruturante do casamento, os cânones V e VI que trataram da indissolubilidade do matrimônio, tendo a proibição do divórcio como reflexo do modelo monogâmico. O decreto Tametsi condenava o concubinato com gradações dos pecados cometidos e punições aplicáveis, de acordo com os envolvidos e circunstâncias.

12 Ruzyk (2006:195-196). 
a vedação ao estabelecimento de famílias paralelas ao casamento e à união estável, o fato de existir designação própria nas situações em que isso ocorre e a ausência de reconhecimento e proteção estatais. Com relação a esse ponto, Moreira (2016) demonstra que na jurisprudência do Supremo Tribunal Federal - STF e Superior Tribunal de Justiça - STJ também se identifica posicionamento pela existência da monogamia enquanto princípio. Todavia, nota-se que o argumento para a negação de efeitos familiares a tais relações é frequentemente a violação da segurança jurídica.

A partir dessas diferentes posições, da exposição acerca da natureza dos princípios e regras, da origem da monogamia enquanto forma de organização da família e sua incorporação pelo ordenamento jurídico (através da identificação dos dispositivos legais que tangenciam a matéria), nos parece ter mais razão a doutrina que defende ser a monogamia um princípio jurídico das relações conjugais no Direito de Família brasileiro. Como dito, as regras derivam de princípios que carregam valores que a sociedade visa proteger. Considerando que o modelo monogâmico foi posto como um padrão na sociedade brasileira e representaria um valor, houve uma produção legislativa nesse sentido.

Contudo, não nos parece totalmente correta a afirmação de parte da doutrina de que os dispositivos infraconstitucionais mencionados teriam como fim último a proteção do modelo monogâmico de família. Dentre os exemplos apresentados, apenas derivariam diretamente do princípio da monogamia as regras atinentes ao dever de fidelidade recíproca entre os cônjuges, o dever de lealdade entre os companheiros na união estável, a denominação de concubinato para as relações não eventuais entre impedidos de casar e o adultério como possível causa de dissolução da sociedade conjugal. Quanto às demais, seria mais razoável afirmar que protegem a boa-fé e a segurança jurídica, princípios gerais do ordenamento, como já mencionado.

Isso acontece porque tais regras parecem projetar sua proteção em outro bem jurídico que não a garantia de exclusividade, mas a confiança e a segurança de ser o único parceiro envolvido na relação conjugal, de forma a evitar surpresas; seja entre aqueles que integram essa relação, seja perante a própria sociedade. Desses dois princípios gerais, parece derivar, por exemplo, a reprimenda legal mais severa relativa à matéria: a tipificação penal de bigamia. O que nos conduz a essa hipótese é a ausência de um tipo penal para a mera existência de uma relação extraconjugal ${ }^{13}$, ou mesmo a constituição de outra união estável, mas tão somente o duplo registro, público e solene perante o Estado, de outro casamento. Tem-se, nesse caso, uma violação da boa-fé e da segurança jurídica, próxima a uma fraude à ordem social, aos registros públicos, à presunção de veracidade relativa aos estados civis.

Remetendo à teoria de Engels (1984), parece a monogamia visar, de fato, muito mais uma questão de cunho patrimonial (ou utilitarista ${ }^{14}$ ) do que amoroso. Isso

13 O que Ruzyk (2006:195-195) chama de poligamia exógena, ou seja, "conjugalidades exteriores a uma comunidade familiar originária (...)".

14 Nas palavras de Souza \& Rêgo (2013:189) que ao fazerem menção à teoria de Engels apontam que o objetivo da monogamia era legitimar o poder patriarcal e proteger o patrimônio familiar, o que aproximaria o instituto de uma regra utilitarista. 
porque os demais dispositivos cíveis apresentados como assecuratórios da monogamia parecem mais inclinados a proteger a segurança jurídica dos interesses patrimoniais daqueles com os quais se agiu com quebra de boa-fé numa relação conjugal, senão vejamos: impedimento para casar sendo pessoa já casada, a vedação de doação de bens do cônjuge adúltero ao concubino, a vedação da nomeação do concubino como herdeiro ou legatário do testador casado, a extinção do direito a alimentos do credor que vier a ter relação concubinária, a impossibilidade de o concubino receber alimentos, a impossibilidade de o concubino figurar como beneficiário de seguro de vida do consorte.

Porém, sendo a boa-fé princípio geral do ordenamento, entendemos ser ele hierarquicamente superior ao princípio específico da monogamia, devendo prevalecer em caso de eventual conflito. Esse aspecto, nos parece, permitiria o reconhecimento de uma união poliafetiva que, ainda que viole este último, pudesse atender às exigências do primeiro, o que será explorado a seguir.

\section{Configuração jurídica de família: requisitos essenciais}

A Constituição Federal traz em seu art. 226, caput, a previsão de especial proteção estatal à família, elevando-a a pilar da sociedade brasileira. De acordo com Farias \& Rosenvald (2009), tal conceito é plural e indeterminado, prevendo uma verdadeira "cláusula geral de inclusão".

Assim, o rol de entidades familiares apresentados nos parágrafos do referido dispositivo teria natureza não taxativa, devendo sobressair, para além de um elenco de formatos possíveis, a perspectiva da função social desempenhada pela família, esta sim merecedora de proteção legal. Isso porque, como ensina Lôbo (2002), não é sobre a família em si que recai a proteção constitucional e sim sobre esse locus de realização subjetiva do indivíduo, uma vez que a Constituição tem como fim a realização da pessoa humana. Dessa forma, pode-se dizer que a Lei Maior não traz requisitos para a configuração da família, mas aponta para a existência de um princípio constitucional específico tendo em vista sua importante função social: a proteção da família. Não sem razão, tem sido desenvolvida a concepção de famíliainstrumento em substituição à família-instituição.

Nessa perspectiva, para além da entidade familiar decorrente do casamento, da união estável e a monoparental (previstas expressamente na Constituição), outras configurações têm sido reconhecidas, ampliando o conceito, a exemplo da anaparental ${ }^{15}$, da pluriparental ${ }^{16}$, da homoafetiva.

15 Relação que possui vínculo de parentesco, mas não possui vínculo de ascendência e descendência, a exemplo de dois irmãos que convivem juntos.

16 Relação que surge do desfazimento de vínculos familiares anteriores e criação de novos vínculos, a exemplo de um casamento ou união estável do qual houve descendentes de um ou ambos os membros que passam a conviver juntos. 
Nota-se que as novas categorias, ainda que não preencham os requisitos legais, têm como legitimadores o afeto e o animus de constituir família, elementos que unem os membros em torno do sentimento de pertencimento a esse grupo social especial. Não por acaso é amplamente reconhecido pela doutrina o princípio da afetividade que rege as entidades familiares e se apresenta como específico do Direito de Famíliai ${ }^{17}$.

Presente o afeto, o animus e sendo uma situação regida pela boa-fé, é possível dizer de um verdadeiro direito subjetivo de constituir família na medida em que a instituição familiar é instrumento de realização da personalidade e felicidade de seus membros. No histórico julgamento em 2011 da ação direta de inconstitucionalidade ADI 4277/DF no STF, que reconheceu a união homoafetiva como entidade familiar, há menção por ministros a esse direito como sendo fundamental.

Particularmente em relação à união estável, o Código Civil traz em seu art. 1.723 os requisitos exigidos para a configuração: convivência pública, contínua e duradoura, estabelecida com o objetivo de constituir família.

Analisando cada um desses requisitos, percebe-se a exigência de que a relação seja revestida de "publicidade", ou seja, que seja notória aos olhos da sociedade. Conforme alerta Farias \& Rosenvald (2009), esse aspecto está mais ligado ao campo probatório da existência da relação convivencial do que para ser propriamente um elemento caracterizador. Complementando essa afirmação, acredita-se que também está relacionado a um aspecto de controle, isto é, de verificação da existência de boa-fé entre os membros, no sentido de uma relação que não ocorre "às escondidas". Continuando nos requisitos, a relação deve ser "contínua", apresentando certa estabilidade. Isso significa que não deve haver interrupções temporais capazes de prejudicar a convivência e o compartilhamento de vida próprios das relações familiares. Associada a essa ideia de estabilidade, o dispositivo prevê também que a relação seja "duradoura" e que, portanto, desenvolva-se em certo período no tempo (apesar de não haver qualquer pré-definição de tempo mínimo). Por fim, e talvez um dos mais importantes, a relação deve ter "objetivo de constituir família”. Trata-se de um requisito finalístico (chamado até aqui de animus), que a distingue, por exemplo, de um namoro.

A análise desses requisitos se mostra relevante na medida em que mesmo antes do reconhecimento jurídico, a união estável se impôs enquanto entidade familiar na sociedade a partir da constatação de ser a mesma uma família de fato, independentemente de prévia previsão legal. Em outras palavras, tais requisitos fixados posteriormente na lei civil apenas transportaram para o mundo jurídico o que já ocorria na realidade, quando um casal, a despeito de não celebrar o casamento, opta por viver como se casado fosse, configurando uma família não menos importante do que aquela oriunda do vínculo matrimonial. Isso é muito importante porque o que se verificou foi um caminho inverso: a realidade moldou o Direito, e não o contrário. Esse fenômeno tem sido observado quando do alargamento do rol de entidades familiares

17 Por todos:Azevedo (2016) queaborda o papel doafeto comovetor para entendimentos contemporâneos no Direito de Família, incluindo paternidade socioafetiva e indenização por abandono afetivo. 
a fim de incorporar formatos não previstos, mas que se apresentam inexoravelmente na ordem social como "família”, caso, por exemplo, da união homoafetiva.

\subsection{O reconhecimento de uniões poliafetivas}

Na atualidade, uma configuração familiar tem buscado reconhecimento: a união poliafetiva. Como dito anteriormente, para fins deste trabalho, adota-se essa terminologia com um recorte semântico específico: uma relação conjugal envolvendo mais de duas pessoas e que apresente os elementos apontados como essenciais à configuração de uma união de fato: afetividade, publicidade, estabilidade, animus de constituir família.

Não obstante o enfoque acima, cabe pontuar, ainda que sucintamente, a existência de diferentes concepções e formatos que poderiam ser agrupados na categoria "poliamor"18, assim considerado, utilizando-se da definição de Cardoso (2010), como uma relação não-monogâmica responsável (consensual). Segundo o autor, o próprio surgimento da palavra "poliamor" na década de 90 é marcado pela diversidade de entendimentos, aparecendo em dois contextos distintos. Um de conotação espiritual e religiosa no âmbito da Igreja de Todos os Mundos (um grupo neo-pagão), que primeiramente utilizou a palavra poly-amorous e, posteriormente, polyamory para se referir às pessoas que tivessem ou quisessem ter relações com mais de uma pessoa simultaneamente. A segunda vertente seria menos transcendentalista, tendo surgido a partir de um grupo na internet voltado a debater sobre relações não monogâmicas consensuais, quando a palavra polyamory teria sido empregada para substituir relações não-monogâmicas. Entendia-se não ser adequado usar uma palavra negativa para transmitir uma ideia que deveria ter seu próprio campo de significação.

Ilustrando as múltiplas possibilidades de configurações poliamoristas, Pilão \& Goldenberg (2012) identificam ao menos três formatos: quando todos os envolvidos se relacionam entre si ("casamento em grupo"), quando cada um tem um relacionamento poliamorista distinto dos parceiros (e, nesse caso, os namorados de um não se relacionam entre si), ou quando um dos integrantes é poliamorista e o outro não (relação mono/poli). Tais modelos ainda se subdividem em "aberto" ou "fechado", o que significa a exigência ou não de fidelidade entre os envolvidos.

Feitas tais considerações e retomando o formato poliamoroso objeto deste trabalho, nota-se que ele preenche todos os requisitos exigidos para a união estável - entidade familiar regulada pelo ordenamento jurídico - com exceção de não se tratar de um casal, mas de mais de duas pessoas. A diversidade de sexo costuma estar presente ${ }^{19}$, embora não interfira no seu enquadramento. Preenchidos (quase)

18 Por todos: Cardoso (2010).

19 Das reportagens veiculadas na imprensa relatando os casos levados a registro em cartório mediante escritura pública em todos foi verificada a diversidade de sexos. Por todos: Amâncio (2016). 
todos os requisitos de uma união estável, seu reconhecimento encontraria óbice no princípio da monogamia.

Contudo, como exposto, apesar de considerar a monogamia um princípio, tratase de princípio específico que rege as relações conjugais formadas pelo casamento e pela união estável. Como temos defendido até aqui, numa escala hierárquica dos princípios jurídicos, os específicos sucumbem diante de eventual colisão com os fundamentais. Assim, se é verdade que a monogamia é um princípio no qual a união poliafetiva encontraria obstáculo, a igualdade, a liberdade e o pluralismo são alguns dos princípios fundamentais em que repousaria sua validade. Além disso, apesar de não disposto expressamente, é possível dizer de um direito subjetivo de constituir família tendo em vista a especial proteção conferida pela Constituição Federalà família e o reconhecimento de ser ela entidade eletiva, voltada à formação da identidade e da realização de direitos da personalidade também protegidos constitucionalmente. Assim, concretizando princípios e direitos fundamentais, a família visa, em última análise, garantir a dignidade da pessoa humana.

A liberdade está representada na Constituição Federal pelo princípio da legalidade a partir do qual "ninguém será obrigado a fazer ou deixar de fazer alguma coisa senão em virtude de lei”. Esse dispositivo traz um comando de não intervenção do Estado quando não houver uma lei que determine sua atuação. E, mais do que isso, subentende que há esferas da vida dos indivíduos não permeáveis ao crivo estatal, à vontade geral representada pelas leis. Há questões que dizem respeito unicamente aos seus titulares que a exercem e vivenciam, tendo em vista estar relacionadas à autodeterminação. Assim deve ser entendida a eleição do formato familiar ou a forma pela qual uma pessoa expressa sua afetividade. São campos regidos pelo princípio específico da não intervenção do Estado - especialmente quando envolver a intimidade -, pois dizem respeito unicamente às pessoas envolvidas.

A esse respeito, Multedo (2017) aponta que o princípio da dignidade da pessoa humana tem como um de seus pilares a liberdade individual que na esfera existencial significa a autonomia dos indivíduos de determinarem seu projeto de vida. E como decorrência, tem-se a necessidade de se preservar espaços de não interferência estatal, traçando-se também justificativas adequadas às normas do sistema jurídico para que seja possível analisar até que ponto são legítimas as atuações legislativas e judiciárias sobre as escolhas que recaem sobre a esfera íntima dos indivíduos. Sendo a intimidade e a vida privada direitos fundamentais, a escolha do modelo conjugal ou convivencial que melhor atenda à realização de cada pessoa se coloca como exemplo do exercício dessa liberdade.

Também nesse sentido, Sarmento (2016) destaca que o melhor entendimento do conteúdo do princípio da dignidade da pessoa humana é “(...) um bloqueio constitucional às intervenções estatais no campo da moralidade privada, atinente às escolhas de vida das pessoas que não afetem direitos de terceiros ou bens jurídicos coletivos relevantes"2o.

20 Sarmento (2016:71-72). 
Considerando a noção de família como instrumento de realização pessoal, de projeção existencial, há necessidade de se respeitarem esses espaços, não sendo legítima a intervenção de terceiros, bem como do Estado, quando esta não se justificar tendo em vista a proteção da pessoa. Isso porque, conforme analisa Multedo (2017) a intervenção do Estado na regulação das relações conjugais e convivenciais inverte os valores constitucionais, porque não há como sustentar que as pessoas tenham que se adequar a um modelo que atenda aos interesses da sociedade e do Estado e não aos dos próprios indivíduos.

Trazendo essa reflexão para as uniões poliafetivas, parece razoável afirmar que as normas do Código Civil ao imporem um modelo monogâmico para as relações conjugais e convivenciais invadem a esfera da intimidade e vida privada das pessoas. E sob uma perspectiva constitucional, só podem ser consideradas legítimas se têm como função a preservação da pessoa, sua boa-fé e dignidade.

É possível defender que as normas infraconstitucionais que derivam do princípio da monogamia têm como fim a promoção da dignidade humana, quando tutelam interesses pessoais e patrimoniais das pessoas que optam e esperam por ele estar regidas. Lado outro, pode-se entender que a monogamia não deve reger obrigatoriamente todas as relações se os membros assumirem que tais normas não se moldam aos seus interesses pessoais. Em outras palavras, se as pessoas envolvidas numa relação poliafetiva decidem, consensualmente, compartilharem outro modelo conjugal (não monogâmico), não cabe ao Estado dizer que não podem ter esse projeto existencial.

Um dos aspectos defendidos nesse trabalho é que, além dos princípios fundamentais envolvidos, a união poliafetiva, sendo consentida, atende também ao princípio geral da boa-fé. Não há quebra da confiança entre seus membros, já que não só há plena informação quanto a não exclusividade, como se sabe perante a quem ela é exercida. Nesse ponto, a aplicação direta das normas derivadas do princípio da monogamia perderia seu fundamento, pois não se coloca à proteção da pessoa. Pelo contrário, surgem apenas como óbice à realização existencial. Para além disso, é importante destacar que na união poliafetiva, ainda que não se tenha a fidelidade a um único parceiro (já que envolve mais de duas pessoas), mantém-se substancialmente o dever de lealdade entre os membros.

Portanto, se é possível identificar a boa-fé numa ótica interna a essas relações, também o é na externa, ou seja, perante a sociedade, atendendo, inclusive, ao requisito da publicidade. E, particularmente nesse ponto, não há como deixar de reconhecer a lavratura de uma escritura pública de união poliafetiva como um ato demonstrativo de boa-fé e que atua no sentido de concretizar outro princípio geral até aqui mencionado: a segurança jurídica. 


\subsection{O caso das escrituras públicas lavradas no país}

Através de notícias veiculadas na imprensa, tornou-se pública, nos últimos anos, a lavratura de escrituras de união poliafetiva em cartórios nos Estados de São Paulo e Rio de Janeiro ${ }^{21}$. Porém, esse movimento aparentemente inaugurado no país em $2012^{22}$, recebeu um forte golpe: após representação ao CNJ pela Associação de Direito da Família e das Sucessões (ADFAS) requerendo a vedação de tais atos, foi publicada em 2016 uma recomendação aos cartórios para que fosse suspenso o registro de novos documentos. De acordo com o CNJ, até então, tratava-se de uma sugestão aos tabelionatos até que o órgão julgasse o Pedido de Providências ${ }^{23}$ e fossem discutidas as implicações legais, notadamente no Direito de Família, Sucessório e Previdenciário. Mais recentemente, em junho de 2018, após votação apertada no Plenário ${ }^{24}$, houve o julgamento final pela procedência do pedido, com a proibição do registro de união poliafetiva pelos cartórios nacionais. Segundo a maioria dos conselheiros, o documento atesta um ato de fé pública e implicaria o reconhecimento de direitos garantidos a casais ligados por casamento ou união estável.

Apesar do posicionamento do relator do processo de que o CNJ tem competência administrativa (e não jurisdicional) e que, portanto, a decisão não tem o condão de discutir a possibilidade ou não da união poliafetiva - apenas normatiza os atos cartorários em consonância com a previsão legal -, não deixa de representar um retrocesso. Ora, as situações existem e os envolvidos não podem aguardar um posicionamento do Judiciário quanto à viabilidade jurídica para que possam reger seus interesses da forma como julgarem mais adequado.

Uma união estável não se constitui pela escritura pública, ela é um fato. O documento apenas registra a declaração de reconhecimento da união pelos envolvidos que podem também regulamentar os efeitos patrimoniais decorrentes. A formalização muitas vezes é realizada a fim de conferir maior segurança, podendo ser feita no cartório (escritura pública) ou através de contrato particular (contrato de convivência).

21 As reportagens relatam a lavratura de escrituras públicas de união poliafetiva em cartórios de notas de Tupã/SP e Rio de Janeiro/RJ. A respeito: Amâncio (2016).

22 A reportagem relata a relação entre um homem e duas mulheres que viviam juntos há três anos e que oficializaram a união através de uma escritura pública de união estável em cartório de notas de Tupã/SP.

23 No Pedido de Providências n ${ }^{0}$ ooo1459-08.2016.2.0o.oooo apresentado pela Associação de Direito de Família e das Sucessões (ADFAS) ao CNJ constam no polo passivo dois tabelionatos de notas no Estado de São Paulo: Terceiro Tabelião de Notas e Protesto de Letras e Títulos de São Vicente e Tabelião de Notas e de Protesto de Letras e Títulos da comarca de Tupã. O Pedido de Providências foi distribuído em 04/04/16 tendo como órgão julgador a Corregedoria que fiscaliza a atuação dos cartórios no país.

24 O Pedido de Providências teve seu julgamento iniciado em 25/04/18, mas foi interrompido por pedido de vista. Em 26/o6/18 foi julgado procedente por maioria no Plenário do CNJ, tendo recebido oito votos pela proibição do registro. Houve cinco votos de divergência parcial no sentido de ser possível registrar através de escritura pública a convivência de três ou mais pessoas por coabitação sem, no entanto, equiparar essa associação à união estável e à família. Houve, ainda, um voto pela improcedência do pedido, ou seja, para permitir a lavratura de escrituras de união poliafetiva pelos cartórios. 
Tendo em vista uma união poliafetiva que se concretiza na realidade fática, a formalização poderia conferir maior segurança jurídica (especialmente no tocante às questões patrimoniais) até mesmo quando de eventual reconhecimento judicial. É legítima a preocupação em se definir previamente, por exemplo, o regime de bens que lhes será aplicado ${ }^{25}$. Não pode ser negado o direito das pessoas de gerirem suas vidas em um campo em que são as únicas titulares e destinatárias dos direitos.

Nesse sentido, sustenta-se que, em que pese a escritura pública ter natureza meramente declaratória, seria instrumento apto a oficializar uma união de fato, conferindo publicidade e trazendo balizas sobre diversos aspectos e ajudando a solucionar, ainda que pontualmente, eventuais conflitos. Evidentemente, esses documentos têm limites que serão analisados oportunamente pelo Judiciário, especialmente no tocante à filiação, à presunção de paternidade, ao exercício do poder familiar, ao parentesco, enfim, aos diversos desdobramentos jurídicos possíveis.

Ao contrário do que decidiu o CNJ, entendemos que até que o tema seja apreciado judicialmente, não apenas seria necessário permitir como poderia se pensar como recomendável que aqueles que buscam maior segurança jurídica o façam através do registro. Isso porque esses documentos poderão ter importante papel em esclarecer o prévio consentimento dos envolvidos em relação àquele formato familiar, bem como outros aspectos (incluindo a situação dos bens), por exemplo, em caso de dissolução.

Sem dúvida alguma, a questão patrimonial, além de fonte de preocupação para os envolvidos, é também objeto frequente de acionamento do Judiciário em demandas envolvendo o reconhecimento de uniões de fato. Assim, as escrituras poderiam contribuir para a solução desses impasses.

Numa concepção mais ampla, pode-se dizer que as escrituras públicas (ou os contratos particulares de convivência levados à registro) atendem aos princípios gerais da boa-fé e da segurança jurídica, podendo ser vistos como instrumentos de realização desses valores tão protegidos pelo ordenamento jurídico, inclusive - como sustentado neste trabalho - em maior grau do que o aludido princípio da monogamia.

Como já mencionado, Moreira (2016) demonstra, a partir de jurisprudência do STF e STJ, que os Tribunais Superiores têm se filiado ao posicionamento de negar reconhecimento a uniões paralelas ou simultâneas (ou seja, núcleos estabelecidos de forma concomitante), por apenas considerarem possível a existência de uma única família legítima. O principal fundamento das decisões é a segurança jurídica. Contudo, o autor também apresenta precedentes favoráveis ao reconhecimento (em especial no Tribunal de Justiça gaúcho) quando presente a boa-fé na relação dita concubinária. Tais situações, apesar de distintas da união poliafetiva, trazem importantes elementos para o presente debate, pois apontam para dois princípios aqui defendidos como axiologicamente superiores à monogamia: a boa-fé e a segurança jurídica. Princípios estes geralmente visados por quem busca oficializar uma união de fato mediante o registro.

25 Conforme dispõe o art. 1.725 do Código Civil: Na união estável, salvo contrato escrito entre os companheiros, aplica-se às relações patrimoniais, no que couber, o regime da comunhão parcial de bens. 


\section{Considerações finais}

Pelo exposto neste estudo, entendemos ser viável juridicamente a união poliafetiva quando presentes os elementos caracterizadores de uma união de fato (afetividade, publicidade, estabilidade e animus de família), conferindo a ela os efeitos legais próprios das entidades familiares.

Apesar da ausência de previsão legal, isso se dá em atendimento a alguns dos princípios eleitos como fundamentais pela Constituição Federal, a saber: igualdade, liberdade, pluralismo, desdobramentos da cláusula geral da dignidade da pessoa humana, fundamento da República Federativa do Brasil.

Para além deles, em posição imediatamente inferior na escala axiológica do ordenamento, os princípios gerais da boa-fé e da segurança jurídica também despontam como parâmetros legitimadores. A boa-fé se mostra presente quando se verifica que os envolvidos agiram de forma ética, proba, leal, ou seja, quando havia sinceridade e boa intenção entre eles e perante a sociedade na configuração daquela entidade familiar. A segurança jurídica, por sua vez, relaciona-se à confiança de seus membros na estabilidade jurídica daquela situação.

Assim, esses princípios, fundamentais e gerais, autorizam a união poliafetiva e transpõem a suposta barreira imposta pelo princípio específico da monogamia. Este, entendemos, continua a nortear as relações conjugais oriundas do matrimônio e da união estável na medida em que dele derivam regras jurídicas aplicáveis a quem opta (e espera) por ele ser regido.

De todo modo, reconhecemos que há inúmeras questões que tangenciam a temática e muitas respostas ainda estão em aberto. A união poliafetiva é mais um hard case que se apresenta ao Direito de Família. Apenas uma discussão aprofundada e transdisciplinar possibilitará um novo olhar e a busca pela melhor justiça possível, aqui entendida como aquela que concretize os princípios mais relevantes consignados no ordenamento pátrio.

\section{REFERÊNCIAS}

AMÂNCIO, Thiago. (2016). "Casais de 3 ou mais parceiros obtêm união com papel passado no Brasil”. In: FOLHA DE SÃO PAULO. Disponível em < http://www1.folha. uol.com.br/cotidiano/2016/o1/1732932-casais-de-3-ou-mais-parceiros-obtem-uniaocom-papel-passado-no-brasil.shtml>. Acessado em 13/o4/17.

ÁVILA, Humberto. (2007). Teoria dos princípios: da definição à aplicação dos princípios jurídicos. 7 ed. rev. e atual. São Paulo: Malheiros. 
AZEVEDO, Álvaro Vilaça. (2016). "Afeto na relação familiar". Revista Síntese - Direito de Família. $\mathrm{n}^{0}$ 93: p. 69-81, dez./jan.

BOBBIO, Norberto. (1995). Teoria do ordenamento jurídico. (Trad.) Maria Celeste Cordeiro Leite dos Santos. 6⿳亠 e ed. Brasília: Universidade de Brasília - Unb.

BRASILIA. Supremo Tribunal Federal. (2011). Ação Direta de Inconstitucionalidade $n^{0} \quad$ 4277-DF. Disponível em: <http://redir.stf.jus.br/paginadorpub/paginador. jsp?docTP=AC\&docID=628635 $>$. Acessado em 10/04/17.

CARDOSO, Daniel dos Santos. (2010). Amando vári@s - individualização, redes, ética e poliamor. Dissertação (Mestrado em Ciências da Comunicação). Faculdade de Ciências Sociais e Humanas - Universidade Nova de Lisboa. Lisboa.

CARDOSO, Daniel dos Santos. (2007). "Amores plurais situados - para uma metanarrativa sócio-histórica do poliamor". Tempo da ciência: revista de ciências sociais e humanas / Centro de Ciências Humanas e Sociais da UNIOESTE, Toledo. Dossiê Poliamor, $n^{0} 48$, v. 24: p. 12-28, jul./dez.

CONSELHO NACIONAL DE JUSTIÇA. (2016). Corregedoria analisa regulamentação do registro de uniões poliafetivas. Disponível em <http://www.cnj.jus.br/ noticias/cnj/82221-corregedoria-analisa-regulamentacao-do-registro-de-unioespoliafetivas $>$. Acessado em 13/04/17.

CONSELHO NACIONAL DE JUSTIÇA. (2018). Cartórios são proibidos de fazer escrituras públicas de relações poliafetivas. Disponível em <http://www.cnj.jus. $\mathrm{br} /$ noticias/cnj/87073-cartorios-sao-proibidos-de-fazer-escrituras-publicas-derelacoes-poliafetivas $>$. Acessado em 06/o7/18.

DIAS, Maria Berenice. (2012). Escritura de união poliafetiva: possibilidade. Disponível em: <http://www.cartaforense.com.br/conteudo/artigos/escritura-de-uniaopoliafetiva-possibilidade/9753>. Acessado em 17/04/17.

ENGELS, Friedrich. (1984). A origem da família, da propriedade privada e do Estado. (Trad.) Leandro Konder. 9aㅗ ed. Rio de Janeiro: Civilização Brasileira.

FARIAS, Cristiano Chaves de; ROSENVALD, Nelson. (2009). Direito das Famílias. Ed. Rio de Janeiro: Lumen Juris.

GABRICH, Frederico de Andrade. (2007). “O caráter normativo dos princípios”. Revista Meritum (FUMEC). n.2, v.2: p. 373-408, jul/dez. 
GONÇALVES, Helanne Barreto Varela. (2015). "O respeito à liberdade de amar ou a ruptura do modelo monogâmico de família”. Revista Brasileira de Direito Civil em Perspectiva. n.2, v.1: p.178-196, jul/dez.

G1 Bauru e Marília. (2012). União estável entre três pessoas é oficializada em cartório de tupã, SP. In: G1 - Globo.com. Disponível em <http://g1.globo.com/sp/bauru-marilia/ noticia/2012/o8/uniao-estavel-entre-tres-pessoas-e-oficializada-em-cartorio-detupa-sp.html>. Acessado em 13/04/17.

IBDFAM. Instituto Brasileiro de Direito de Família. (2012). Escritura reconhece união afetiva a três. Disponível em <http://www.ibdfam.org.br/noticias/4862>. Acessado em $05 / 07 / 17$.

IBDFAM. Instituto Brasileiro de Direito de Família. (2016). União poliafetiva: escritura é necessária?. Disponível em: http://www.ibdfam.org.br/noticias/5970. Acessado em 05/07/17.

LÔBO, Paulo Luiz Netto. (2002). "Entidades familiares constitucionalizadas: para além do numerus clausus”. Revista Brasileira de Direito de Família. Síntese/IBDFAM, n. 12: p.40-55, jan./mar.

MASSON, Cleber. (2015). Direito Penal - Parte geral. vol. 1, 9ª ed. rev., atual. e ampl. São Paulo: Método. p. 50 e 161.

MOREIRA, Thacio Fortunato. (2016). "Poliamorismo nos tribunais”. Revista Síntese Direito de Família, no 93: p. 18-45, dez./jan.

MULTEDO, Renata Vilela. (2017). Liberdade e família - limites para a intervenção do Estado nas relações conjugais e parentais. Rio de Janeiro: Processo.

OLIVEIRA, Caroline Buarque Leite de. (2017). Poliamor: da aplicabilidade dos direitos e garantias constitucionais à legitimidade jurídica das uniões múltiplas e seus efeitos. Maceió: [Imprensa Oficial Graciliano Ramos].

PEREIRA, Rodrigo da Cunha. (2006). "Uma principiologia para o Direito de Família”. In: CONGRESSO BRASILEIRO DE DIREITO DE FAMÍLIA (5.: 2005: Belo Horizonte, MG) Família e dignidade humana / V Congresso Brasileiro de Direito de Família. São Paulo: IOB Thompson. p. 844-851.

PILÃO, Antonio Cerdeira; GOLDENBERG, Mirian. (2012). "Poliamor e monogamia: construindo diferenças e hierarquias”. Revista Ártemis, ed. v.13: p. 62-71, jan/jul. 
POLI, Luciana Costa; HAZAN, Bruno Ferraz. (2016). "Descortinando invisibilidades: união poliafetiva”. Revista de Direito de Família e Sucessão. n.1, v.2: p. 16-32, jan./jul.

RODRIGUES, Mateus. (2018). Dois anos após conseguir o registro da união poliafetiva, trio do Rio ainda enfrenta problemas burocráticos. Disponível em <https://g1.globo. $\mathrm{com} / \mathrm{rj} / \mathrm{rio}$-de-janeiro/noticia/dois-anos-apos-conseguir-o-registro-da-uniaopoliafetiva-trio-do-rio-ainda-enfrenta-problemas-burocraticos.ghtml>. Acessado em 07/07/18.

RUZYK, Carlos Eduardo Pianovski. "Famílias simultâneas e monogamia”. (2006). In: CONGRESSO BRASILEIRO DE DIREITO DE FAMÍLIA (5.: 2005: Belo Horizonte, MG). Família e dignidade humana / V Congresso Brasileiro de Direito de Família. São Paulo: IOB Thompson, p. 193-221.

SANTIAGO, Rafael da Silva. (2015). "Poliamor e direito das famílias: reconhecimento e consequências jurídicas”. Curitiba: Juruá.

SILVA, Marcos Alves da. (2016). "Da Monogamia: a sua superação como princípio estruturante do direito de família”. Curitiba: Juruá.

SOUZA, Lara Marcelino de; RÊGO, Lorena Nogueira. (2013). "Contornos jurídicos, filosóficos e sociais da monogamia: paradigmas do poliamor no Direito de Família”. Revista FIDES, n. 2, v.4: p. 184-202, jul./dez.

UOL NOTÍCIAS. (2012). 'Estamos documentando o que sempre existiu', diz tabeliã que uniu três. Disponível em: <https://noticias.uol.com.br/ultimas-noticias/ bbc/2012/o8/28/estamos-documentando-o-que-sempre-existiu-diz-tabelia-queuniu-tres.htm>. Acessado em 05/o7/17.

VIEGAS, Claudia Mara de Almeida Rabelo. (2016). "Os efeitos do poliamorismo no direito contemporâneo: uma análise à luz da dignidade da pessoa humana”. Revista Síntese - Direito de Família, no 93: p. o9-17, dez./jan.

Recebido: 15.10.2017

Aceito: 10.09 .2018 